\title{
Assessment on the rates and potentials of soil organic carbon sequestration in agricultural lands in Japan using a process-based model and spatially explicit land-use change inventories - Part 1: Historical trend and validation based on nation-wide soil monitoring
}

\author{
Y. Yagasaki ${ }^{1}{ }^{*}$ and Y. Shirato ${ }^{1}$ \\ ${ }^{1}$ Natural Resources Inventory Center, National Institute for Agro-Environmental Sciences, 3-1-3 Kannondai, Tsukuba, \\ 305-8604, Japan \\ *now at: Terrestrial Ecosystems Management, Hall of Global Environmental Research, Graduate School of Global \\ Environmental Studies, Kyoto University, Yoshida-Honmachi, Sakyo-ku, Kyoto, 606-8501, Japan \\ Correspondence to: Y. Yagasaki (yagasaki.yasumi.7n@kyoto-u.ac.jp)
}

Received: 26 July 2013 - Published in Biogeosciences Discuss.: 27 November 2013

Revised: 22 May 2014 - Accepted: 12 June 2014 - Published: 22 August 2014

\begin{abstract}
In order to estimate a country-scale soil organic carbon (SOC) stock change in agricultural lands in Japan, while taking into account the effect of land-use changes, climate, different agricultural activities and the nature of soils, a spatially explicit model simulation system was developed using Rothamsted Carbon Model (RothC) with an integration of spatial and temporal inventories. Simulation was run from 1970 to 2008 with historical inventories. Simulated SOC stock was compared with observations in a nation-wide stationary monitoring program conducted during 1979-1998.

Historical land-use change, characterized by a large decline in the area of paddy fields as well as a small but continuous decline in the area of orchards, occurred along with a relatively large increase in upland crop fields, unmanaged grasslands, and settlements (i.e. conversion of agricultural fields due to urbanization or abandoning). Results of the simulation on SOC stock change under varying land-use change indicated that land-use conversion from agricultural fields to settlements or other lands, as well as that from paddy fields to croplands have likely been an increasing source of $\mathrm{CO}_{2}$ emission, due to the reduction of organic carbon input to soils and the enhancement of SOC decomposition through transition of soil environment from anaerobic to aerobic conditions.

The area-weighted mean concentrations of the simulated SOC stocks calculated for major soil groups under paddy fields and upland crop fields were comparable to those observed in the monitoring. Whereas in orchards, the simulated
\end{abstract}

SOC stocks were underestimated. As the results of simulation indicated that SOC stock change under managed grasslands and settlements has been likely a major sink and source of $\mathrm{CO}_{2}$ emission at country-scale, respectively, validation of SOC stock change under these land-use types, which could not have been accomplished due to limited availability or a lack of measurement, remains a forthcoming challenge.

\section{Introduction}

Sequestration of soil organic carbon (SOC) in agricultural lands as an option to mitigate global climate change is considered to have significant technical potentials to reduce emission of $\mathrm{CO}_{2}$ or to act as $\mathrm{CO}_{2}$ sink at global scale (Lal, 2004; Smith et al., 2008). It is also considered that this technique has a potential to establish "win-win" solutions in a context of sustainable agriculture (Lal, 2004; Lehmann, 2009) with low abatement cost (Smith et al., 2008). In addition, the SOC sequestration in agricultural lands has been attracting interest from international societies as Article 3.4 of Kyoto Protocol allows parties to include accounting on sinks or sources of $\mathrm{CO}_{2}$, due to SOC stock change in lands under cropland and grazing land management, to meet their target to reduce emissions of greenhouse gases (GHGs). 
In contrast to the prospected low abatement cost, establishing methodologies to ensure accurate measurement or estimation on the stock change of SOC at regional or country scale is amongst the most difficult challenges in implementation of SOC sequestration as a policy to mitigate GHGs emission. The soil carbon dynamics at regional or a country scale is a complex system involving various influencing factors such as climate, soil properties, land-use change, and agricultural practices on farm lands. It is important to take account spatial and temporal variability of these factors. However, difficulties often arise due to limited availability or insufficient resolutions of spatial and temporal inventories of those data.

So far, significant efforts have been taken to estimate potential of agricultural soil carbon sequestration at large spatial scale, such as adoption of spatially explicit land-use change data at global scale (Eglin et al., 2010; Houghton, 2003; Houghton et al., 1999) or at country to regional scale (Houghton et al., 1999; Schulp et al., 2008), application of a process-based model on SOC dynamics (Eglin et al., 2010; Janssens et al., 2005; Li et al., 2003; Piao et al., 2009; Sitch et al., 2008), realistic estimation of agricultural activity and organic amendment input to soils with ensuring mass balance between production and consumption of manure (Mondini et al., 2012).

For SOC stock change in agricultural lands, in particular, it is important to give realistic estimates for the stock and flow of livestock waste and manure so that the estimates should be consistent with estimates for their production, treatment, and consumption (Mondini et al., 2012). A study done by Koga et al. (2011) demonstrated that estimation of a regional-scale SOC stock change could result in figures with large uncertainty due to large variations in parameters used to estimate manure input to soils.

Furthermore, any attempt to use a process-based model to estimate soil carbon sequestration at regional or country scale, would require validation using a large-scale field monitoring data that covers similar size of geographical entity.

In this study, we developed a system to perform estimation on SOC stock change in agricultural lands in Japan, with the objective (1) to provide useful information for decision support for policy making concerning a country-scale potential of soil carbon sequestration, as well as (2) to give estimates on a country-scale SOC stock change to be used in national green house gas inventory reporting to the United Nations Framework Convention on Climate Change (UNFCCC) for the sector of Land Use, Land Use Change and Forestry (LULUCF) or Agriculture, Forestry and Other Land Use (AFOLU), in accordance with Good Practice Guidance for Land Use, Land-Use Change and Forestry (GPG-LULUCF) (Intergovernmental Panel on Climate Change, 2003). In order to complete these objectives, the following conditions should be fulfilled, as we have implemented in the design and construction of the system;
1. Use of spatially explicit land-use change data, rather than statistics on land-use change only weakly associated with other geographical inventories on soil and climate.

2. Application of a process-based model on SOC dynamics with future climate projections, rather than a bookkeeping model (e.g. stock change factor).

3. Realistic estimation of the rate of organic matter input to soils with ensuring mass balance between production and consumption of biomass (manure and plant residue).

4. Estimation of the rate of soil carbon sequestration in both base year and reporting/commitment period in line with Kyoto Protocol to allow net-net accounting with an intention to assist policy making.

Spatial and temporal inventory on soil, land-use change, and climate of historical period were prepared and used to apply process-based model on SOC turnover over agricultural lands in Japan. Simulation output on SOC stock changes for each soil types under different land-use was compared with that obtained from nation-wide stationary monitoring on soils in agricultural lands conducted during 1979-1998 to conduct validation of the simulation system we developed.

\section{Materials and methods}

\subsection{Basic framework of simulation system}

The framework of simulation system we built consists of three major modules (Fig. 1):

Module 1: a set of spatial and temporal inventories comprised of a database of soil, weather, agricultural activity, and land-use change that covers the entire regions of Japan.

Module 2: SOC turnover simulation module, computes changes in SOC stock using the RothC model (Jenkinson et al., 1990) with monthly time interval using the spatio-temporal inventory as input.

Module 3: accounting module, performs accounting for $\mathrm{CO}_{2}$ removal or emission due to SOC stock change for a given commitment period and base period (base year) as defined in Kyoto Protocol (KP), based on the simulated SOC stock change in combination with that of landuse change. The calculation will be executed in compliance with GPG-LULUCF established by The Intergovernmental Panel on Climate Change (IPCC) (IPCC, 2003).

In this study, we used module 1 and 2 only, whereas inclusion of module 3 enables SOC stock change estimation to 


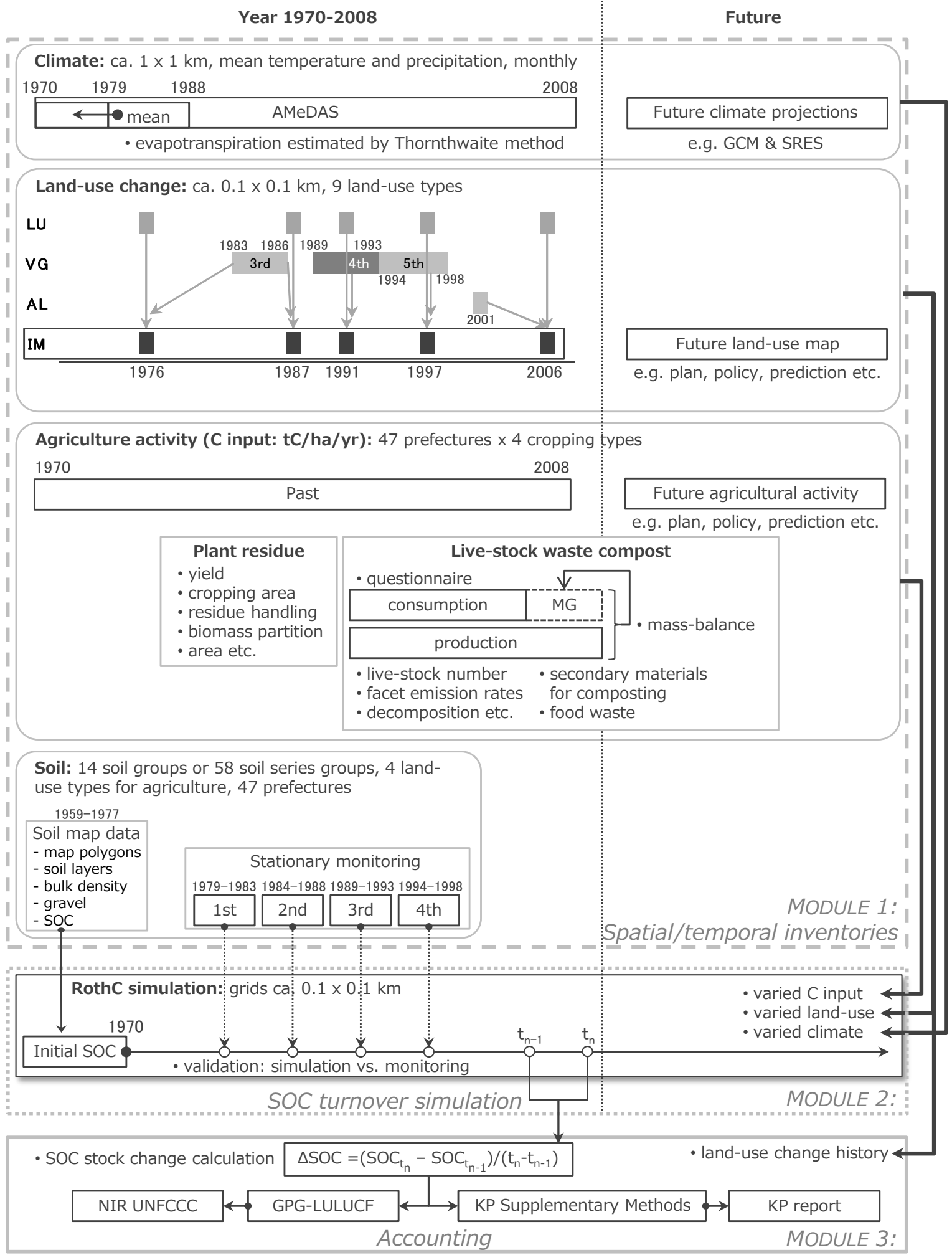

Figure 1. Schematic diagram of the system developed to simulate soil carbon stock change at country-scale using spatially explicit inventories on land-use change, climate, soil, and agricultural activity. The system is designed to be capable to simulate both historical and future soil organic carbon stock change, provided that spatial and temporal inventories are continuous or have appropriate time interval. See the text and Supplement for detailed descriptions on other abbreviated text in figures: SOC - soil organic carbon; LU - land-use map, VG - vegetation map, AL - agricultural field map, IM - interpreted land-use/land-cover map, MG - managed grasslands, GCM - Global Climate Models, SRES - Special Report on Emission Scenarios of IPCC, KP - Kyoto Protocol, and NIR - National Inventory Report. 
be reported as National Inventory Report (NIR) to UNFCCC, as well as a study on the estimation of the potential of SOC stock change in future.

\subsection{Land-use change}

A nation-wide, spatially explicit land-use change data set for reporting or accounting of LULUCF or AFOLU was created by compiling several different geographical data archives to serve an interpreted map product. Three different sources of geographical data on land use and land cover (see the Supplement for details) were compiled and superimposed on a geographical grid system, which covers the whole of Japan. The grid system has a spatial resolution of $1 / 1200$ and $1 / 800^{\circ}$ (3.0 and $4.5 \mathrm{~s}$ ), along latitudinal and longitudinal lines, respectively. The size of an individual cell of the grid is equivalent to a parcel of land with an area of ca. $10000 \mathrm{~m}^{2}$ (1 ha). A decision tree for land-use type identification was created and applied to individual or grouped map legend item(s) in these four different geographical data sources (Fig. 2). As a result, each grid cell was classified into 9 land-use types based on six top-level land categories and their subdivisions consistent with GPG-LULUCF: (1) paddy fields (PD), (2) upland crop fields (UP), (3) orchards (OC), (4) managed grasslands (MG), (5) unmanaged grasslands (UG), (6) forest lands (FL), (7) wetlands (WL), (8) settlements (ST), and (9) other lands (OL). In total, five interpreted maps were created for 1976, 1987, 1991, 1997, and 2006, respectively, as a database table with geographic references using PostgreSQL 9.0.13 (PostgreSQL Global Development Group, 2013) and PostGIS 1.5.8 (Refractions Research Inc, 2012).

Details on each geographical data sources, as well as method of land-use/land-cover interpretation, are described in the Supplement.

\subsection{Soil organic carbon dynamics}

We used Rothamsted carbon model (RothC), or RothC-26.3 (Coleman and Jenkinson, 1999; Jenkinson et al., 1990) to simulate turnover of SOC. This model simulates changes in SOC stock in a surface soil layer with a monthly time interval under given environmental conditions and rate of organic matter input to soil. The model expresses the process of the decomposition of soil organic matter (SOM) and accumulation with five hypothetical SOC components having different intrinsic decomposition rate constants, namely, decomposable plant materials (DPM), resistant plant materials (RPM), microbial biomass (BIO), humus (HUM), and inert organic matter (IOM).

In addition to the original RothC-26.3, we used two other versions of the RothC model with modifications extending its functionality to be applicable to a wider range of land-use and soil types (Table 1):
1. RothC-26.3: for all land-use types other than paddy fields with soil types other than Andosols.

2. RothC-26.3_p: for paddy fields that hold water-logged conditions for some periods in a year (Shirato and Yokozawa, 2005).

3. RothC-26.3_v: for all land-use types excluding paddy fields with Andosols. A simple tuning of the decomposition rate constant of HUM, expressed as a function of the size of pool of active aluminium bound to humus, was introduced (Shirato et al., 2004). Shirato et al. (2004) introduced a stability factor " $H$ " (though this was expressed as " $H(f)$ " in original text, we alter the expression for the sake of convenience and clarity) for this tuning using the following equation:

$$
\begin{gathered}
\mathrm{SOC}_{\mathrm{obs}}-\mathrm{SOC}_{\mathrm{sim}}=\mathrm{HUM}_{\mathrm{obs}}-\mathrm{SOC}_{\mathrm{sim}} \\
=(H-1) \times \mathrm{HUM}_{\mathrm{sim}} \\
H=\mathrm{SOC}_{\mathrm{obs}}-\left(\mathrm{SOC}_{\mathrm{sim}}-\mathrm{HUM}_{\mathrm{sim}}\right) \mathrm{HUM}_{\mathrm{sim}} .
\end{gathered}
$$

Decomposition rate constant of the HUM pool in original RothC model was then divided by $H$ so that model simulation output agreed with the observed SOC content. Shirato et al. (2004) obtained the linear regression model to obtain the best fit of the values of $H$ using sodium-pyrophosphate extractable aluminium $\left(\mathrm{Al}_{\mathrm{p}}\right)$ based on long-term monitoring data at 32 sites with Japanese Andosols:

$H=1.20+2.50 \mathrm{Al}_{\mathrm{p}} \quad\left(r^{2}=0.518\right)$.

Another recent modification that employs phosphate adsorption coefficient (PAC), a more commonly available data attribute in the soil database, as a single parameter for this tuning (Takata et al., 2011), was employed in this study to assure a model simulation run across the entire country. The PAC is used as an indicator for the content of amorphous aluminium and iron soil mineral compounds, as well as criterion for the Andosol group in the Japanese soil classification system. Using similar approach and almost identical data set, Takata et al. (2011) obtained another empirical model using PAC to obtain the values of $H$ :

$H=1.126 \exp (0.00077 \mathrm{PAC}) \quad\left(r^{2}=0.57\right)$.

Furthermore, both models differ in their formulation with respect to soil attributes taken into account and thus were leaving space for interpretation or mechanistic explanations; however, this should be regarded as a simple empirical model made for practical use. Due to limited data availability of $\mathrm{Al}_{\mathrm{p}}$, some previous studies applied Eq. (3) with employing estimation of the $\mathrm{Al}_{\mathrm{p}}$ from soil organic carbon content. However, such an approach may cause a risk of circular logic as discussed by Takata et al. (2011) and thus should be avoided. 


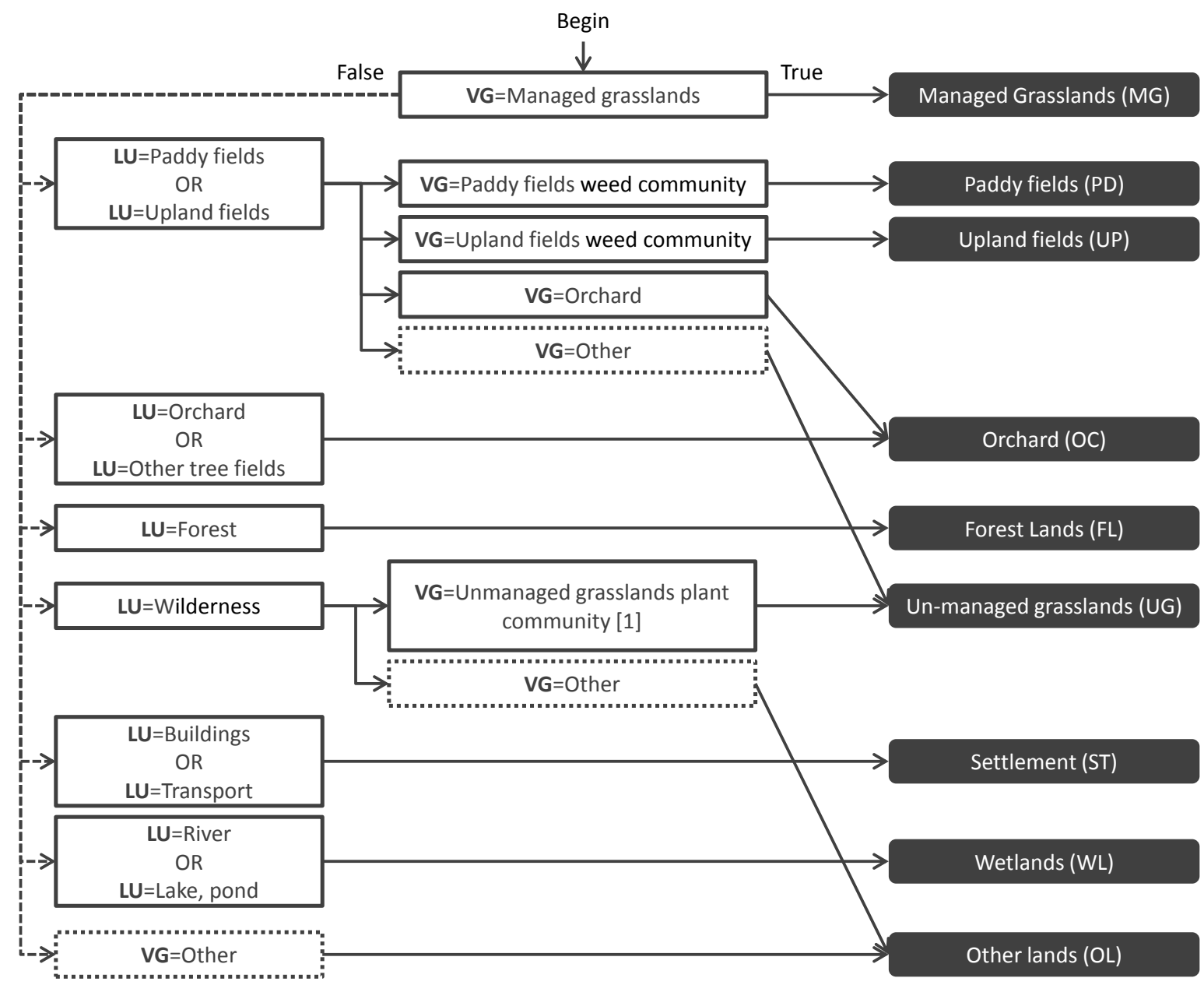

Figure 2. Diagram of interpretation of land-use or land-cover type using multiple different sources of land-use or land-cover map: LU Land Use Fragmented Mesh Version 1.1 in National Land Numerical Information, created by Ministry of Land, Infrastructure, Transport and Tourism, the Government of Japan; VG - vegetation map from Vegetation Naturalness Survey conducted in National Survey on the Natural Environment, created by Ministry of Environment (MOE), the Government of Japan. Note that for land-use/land-cover interpretation for 2006, VG was substituted by another geographical data source, AL, agricultural land map from Basic Survey on Improvement of Agricultural Production Base, produced by Ministry of Agriculture, Forestry, and Fisheries (MAFF), the Government of Japan, due to a lack of data in VG data set in this period. For details on each geographical data sources, see the Supplement.

\subsection{Climate}

Observations in Automated Meteorological Data Acquisition System (AMeDAS) were used for climate input data for the simulation, for period 1979-2009. The data set had been downscaled by Seino (1993) to $1 / 120^{\circ} \times 1 / 80^{\circ}(30 \mathrm{~s} \times 45 \mathrm{~s})$, along latitudinal and longitudinal lines, (Okada et al., 2009; Seino, 1993). The size of the grid cell is equivalent to a parcel of land with an area of ca. $1 \mathrm{~km}^{2}$ (100 ha).

Mean monthly air temperature, monthly precipitation, and monthly potential evapotranspiration were calculated or directly obtained from these data sources and used as input for RothC. Monthly potential evapotranspiration was estimated based on mean monthly temperature in the AMeDAS and latitude of each grid cell using a Thornthwaite equation (Thorn- thwaite, 1948). For 1970-1978, means of 1979-1989 in each grid cell were calculated and used.

\subsection{Soil}

For the initial set-up of total SOC levels of each geographic entity in the simulation, representative values of total SOC $\left(\mathrm{Mg} \mathrm{Cha}^{-1}\right)$ and clay content (\%) for the top 0-30 $\mathrm{cm}$ layer were calculated for each soil series group with different land use and in different prefecture, using two different nationwide soil inventories conducted by the Ministry of Agriculture Fishery and Forestry (MAFF) of Japan and agricultural experiment stations in prefectures: 
Table 1. Settings in simulation with regard to model version and data source used to determine rate of organic carbon input to soils for plant residue and manure in different land-use types.

\begin{tabular}{|c|c|c|c|c|}
\hline Symbol $^{1}$ & Land-use & Model & Plant residue & Manure \\
\hline $01 \mathrm{PD}$ & Paddy fields & $\mathrm{RP}^{2}$ & Estimation from stat. ${ }^{5}$ & Farmer questionnaire 8 \\
\hline 02 UP & Upland crop fields & $\mathrm{RO}^{3}, \mathrm{RV}^{4}$ & Estimation from stat. ${ }^{5}$ & Farmer questionnaire 8 \\
\hline $03 \mathrm{OC}$ & Orchards & $\mathrm{RO}^{3}, \mathrm{RV}^{4}$ & Estimation from stat. ${ }^{5}$ & Farmer questionnaire 8 \\
\hline $04 \mathrm{MG}$ & Managed grasslands & $\mathrm{RO}^{3}, \mathrm{RV}^{4}$ & Estimation from stat. ${ }^{5}$ & Mass balance $^{9}$ \\
\hline $05 \mathrm{UG}$ & Unmanaged grasslands & $\mathrm{RO}^{3}, \mathrm{RV}^{4}$ & 3.8 $\mathrm{MgCha}^{-1} \mathrm{yr}^{-16}$ & No manure input \\
\hline $06 \mathrm{FL}$ & Forest lands & $\mathrm{RO}^{3}, \mathrm{RV}^{4}$ & $2.0 \mathrm{MgCha}^{-1} \mathrm{yr}^{-17}$ & No manure input \\
\hline $08 \mathrm{ST}$ & Settlements & $\mathrm{RO}^{3}, \mathrm{RV}^{4}$ & & No manure input \\
\hline $09 \mathrm{OL}$ & Other lands & $\mathrm{RO}^{3}, \mathrm{RV}^{4}$ & & No manure input \\
\hline $07 \mathrm{WL}$ & Wetlands & - & - & - \\
\hline
\end{tabular}

${ }^{1}$ PD: paddy fields, UP: upland crop fields, OC: orchards, MG: managed grasslands, UG: unmanaged grasslands, FL: forest lands, WL: wetlands, ST: settlements, OL: other lands.

2 RP: RothC-26.3_p.

3 RO: RothC-26.3.

${ }^{4}$ RV: RothC-26.3 v.

${ }^{5}$ Estimation based on various agricultural statistics such as yields, cropping area, field area, etc., in combination with various parameters on agricultural management practices and crop characteristics taken from literatures.

${ }^{6}$ Estimation for grasslands employed in Shirato et al. (2004).

${ }^{7}$ Estimation for Forest lands employed in Shirato et al. (2004).

${ }^{8}$ Estimation based on results of questionnaires to farmers archived by nation-wide soil stationary monitoring program (Dojo kankyou kiso chousa, in Japanese).

${ }^{9}$ Estimation based on mass-balance calculation on supply (production) and demand (applications) of manure compost. Amount of manure applied in managed grasslands is calculated by subtracting the sum of amount of manure applied in paddy fields, upland crop fields, and orchards from total amount of produced manure in the same year.

1. Soil survey for soil map compilation, conducted during 1959-1978 (Chiryoku hozen kihon chousa, in Japanese) (Nihon Dojo Kyoukai, 2002).

2. Stationary monitoring program, conducted during 1979-1998 (Dojo kankyou kiso chousa, in Japanese) (Agricultural Production Bureau, Ministry of Agriculture Forestry and Fisheries, 2008)

First, for each data sets, data records on soil horizons were sub-divided into a series of consecutive layers with $1 \mathrm{~cm}$ thickness and rearranged by order of layer depth, using ordinary functions of structured query language (SQL) on PostgreSQL. Next, using a sub-data set of the survey in 19591978, vertical distribution patterns of SOC (\%), bulk density (BD) $\left(\mathrm{Mg} \mathrm{m}^{-3}\right)$, and clay content (\%), expressed as a relative proportion of the value of attributes in each $1 \mathrm{~cm}$ layer compared with those in a top $0-1 \mathrm{~cm}$ layer, were analyzed for each soil series group and land-use type. Using this vertical distribution pattern, soil attributes data from stationary monitoring were vertically interpolated or extrapolated with $1 \mathrm{~cm}$ intervals in case data were missing down to a depth of $30 \mathrm{~cm}$. Estimates for SOC $\left(\mathrm{Mg} \mathrm{Cha}^{-1}\right)$ and clay content (\%) for a top 0-30 cm layer were obtained as the sum and mean of each attributes through the first to 30th layers, respectively. For gravel content, gravel content in air-dried soil was used for the survey in 1959-1978, as a substitute for gravel content in soil core samples to be used for SOC stock calculation. Whereas for stationary monitoring data set, no data on gravel content was available. We employed gravel con- tent data observed in latest soil carbon survey project ( $D o-$ jou tanso chousa jigyou, in Japanese), having been conducted since 2008 (Ondanka taisaku dojou kinou chousa kyougikai, 2013), and applied it to the SOC stock estimation for the stationary monitoring data set with assuming no major changes in gravel content occurred since 1959-1978.

For details on the soil inventories, as well as the methodology of the measurement of SOC concentration in those soil inventories, see the Supplement.

\subsection{Agricultural activity}

Average annual rates of organic carbon input to soil during 1970-2008 were estimated for four land-use types of agricultural lands (paddy fields, upland crop fields, orchards, and managed grasslands) in 47 prefectures using a toolkit called DTK (after Dojo tanso kun, in Japanese), which was originally developed by Agricultural Production Bureau (APB), Ministry of Agriculture Forestry and Fishery (MAFF), Japan. The DTK is comprised of a collection of spread sheets with stratified calculation modules and contains data tables for national agricultural statistics (e.g. yields, cropping area, etc.), survey data on material flow including treatment of plant residue and livestock waste by farmers, and physicochemical properties of biomass including the decomposition rate during composting. Modifications with a newly updated parameter set and calculation modules were added in the latest version of DTK developed for this study (version 3.0.0), including major updates and revisions for the older version of 
DTK (version 2.2.8 and older; Shirato and Yagasaki, 2012a, b, 2013).

As a main strategy, DTK employs the mix of a top-down approach, based on national agricultural statistics table, and a bottom-up approach, based on results of questionnaire to farmers on their practices conducted in the stationary monitoring, in its framework of calculation to ensure a mass balance between production and consumption of manure compost on an annual base. Rates of annual application of manure compost for each cropping type in different groups of prefectures were calculated based the farmer's questionnaire data collected in the stationary monitoring, which was then assembled for each agricultural land-use type with assumed variations in rotation, except for managed grasslands which had no available data. The average manure compost application rate in managed grasslands was estimated at country level based on the mass balance between production and consumption of manure, by subtracting the sum of the manures applied to paddy fields, upland crop fields, and orchards from the mass of total available manure, which was estimated by unit production of manure and the number of livestock in combination with a set of parameters on manure treatments, including proportion of waste to be used for manure production against other usages such as disposal and incineration.

Belowground carbon input was estimated based on the proportion of below ground biomass against yield of agricultural crops reported in the literature. Selected equations and parameters used in DTK are shown in the Supplement.

\subsection{Simulation}

Simulation was run from 1970 to 2008 using a set of spatial and temporal inventories on climate, agricultural activity, and land-use change. At the start of simulation, in 1970, proportion and size of SOC model compartments in RothC (DPM, RPM, BIO, HUM, and IOM) as well as its total SOC level were assumed to be in equilibrium state and was obtained by executing a long-term simulation with a spin-up period for 10000 years prior to starting year of the simulation with assuming conditions of weather, management, and organic matter input as same as those in 1970. As this set up for initial SOC would cause an artefact in estimation of the rate of soil carbon stock change for some years following the year the simulation began, we used output of the simulation only after 1980 with the assumption that the first 10 years (year 1970-1979) were affected by the undesirable artefact.

To focus only on croplands and grazing lands, aggregations and accounting of $\mathrm{CO}_{2}$ emission were performed only to a limited range of grid cells that would fall into categories of agricultural lands (i.e. paddy fields, upland crop fields, orchards, and managed grasslands) at least one year in a course of land-use change. Hereafter, this extent of land will be referred to as "agricultural lands", as employed in the title of this paper, for the purpose of simplicity.
The rate of organic carbon input to soils under unmanaged grassland and forest lands were assumed to be 3.8 and 2.0 $\mathrm{Mg} \mathrm{Cha}^{-1} \mathrm{yr}^{-1}$ following Shirato et al. (2004), whereas those under settlements and other lands were assumed to be zero (Table 1).

\subsection{Validation of model simulation in 1979-1998}

Temporal changes in SOC stock predicted by simulation were compared with those observed in the nation-wide soil stationary monitoring during 1979-1998 to assess validity of model prediction in this period. For this comparison, seven major soil groups based on a Japanese soil classification system on cultivated lands (National Institute for Agricultural Sciences, 1983) were selected, which accounted for $88 \%$ of total area of all 16 soil groups of agricultural lands in Japan (Obara, 2000). Using the stationary monitoring data, for each waves of the monitoring survey (first wave: 1979-1983; second wave: 1984-1988; third wave: 1989-1993; fourth wave: 1994-1998), area-weighted mean values of SOC stock in surface 0-30 cm layer in unit of $\mathrm{Mg} \mathrm{Cha}^{-1}$ were calculated for each soil groups under different land-use types (excluding managed grasslands due to limited data availability).

For simulated SOC stock, mean SOC stock was calculated for collection of grid cells grouped by soil groups and landuse types at country scale, for the period corresponding to the waves of the stationary monitoring survey.

\section{Results}

\subsection{Land-use change}

During 1970-2006, changes in the area of different landuse types were characterized by a large decline in paddy fields and orchards along with a large increase in the area of unmanaged grasslands, settlements, and upland crop fields (Fig. 3). From 1970 to 2006, the area of paddy fields and orchards declined from 2.9 to $1.6 \mathrm{Mha}$ and from 0.6 to $0.3 \mathrm{Mha}$, respectively. Correspondingly, the area of unmanaged grasslands, settlements, and upland crop fields increased largely, from 1.0 to $1.5-1.6 \mathrm{Mha}$, from 0.06 to $0.4-0.5 \mathrm{Mha}$ and from 1.5 to $1.8 \mathrm{Mha}$, respectively. In addition, managed grasslands and other lands were found to have increased, though relatively small, from 0.5 to $0.6 \mathrm{Mha}$ and from 0.08 to $0.2 \mathrm{Mha}$, respectively (Fig. 3).

\subsection{Agricultural activity in 1970-2008}

Estimated overall input of organic carbon to unit area of soils (sum of plant residue, manure, slurry, and excreta) during 1970-2008, expressed as weighted mean values for the entire country, for paddy fields, upland crop fields, orchards, and managed grasslands covered a range of 2.1-2.8, 2.1-3.1, 1.5-2.0, and 2.5-6.8 $\mathrm{MgC} \mathrm{ha}^{-1} \mathrm{yr}^{-1}$, respectively (Fig. 4a). In paddy fields, the overall input rate gradually increased 


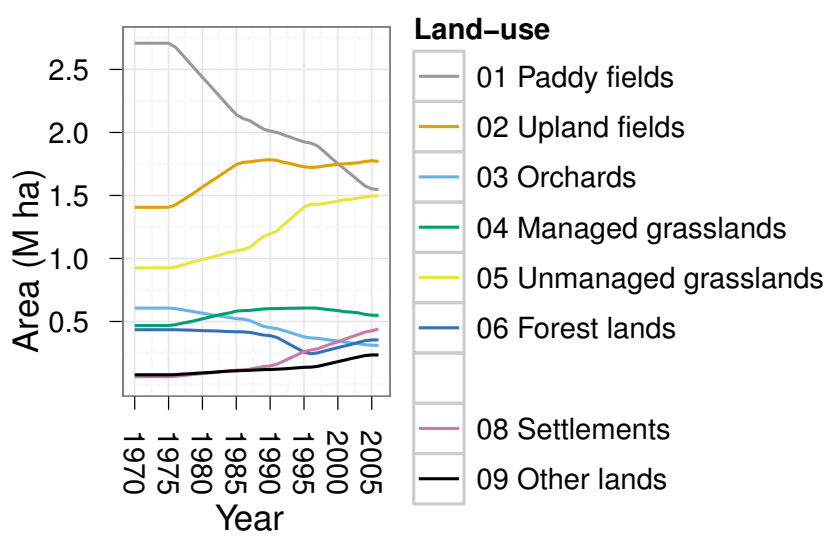

Figure 3. Temporal changes in the area of different land-use types in agricultural land of Japan used in the simulation during 19702008.

during 1970-2008, due to a relatively greater increase in plant residue input that overcame the decline in manure input (Fig. 4a). The increase in plant residue input in paddy fields was explained mostly by increases in the proportion of farmers who employed rice straw incorporation into soils in preference to other treatments (e.g. compost production, roughage, livestock bedding, production of handicraft, and incineration), documented in a survey report on actual conditions of rice production practices (e.g. changed from 47 to $73 \%$, from 1979 to 2008 , as a mean of 5 regions).

In upland crop fields, the overall input rate declined with time due to a decline in manure input (Fig. 4a). In orchards, the overall input rate slightly increased with time characterized by a slight increase in input rate of both plant residue and manure found in mid-1990s (Fig. 4a). In managed grasslands, the overall input rate increased rapidly from 1970 to mid-1990s, followed by a plateau until 2008, due to changes in manure input (Fig. 4a).

In managed grasslands, the rapid and large increase in manure input rate from 1970 to mid-1990s was due to an increase in production of livestock waste compost caused by an increase in the number of livestock (cattle, pig, and poultry) in combination with decline in the consumption rate of livestock waste compost in three other types of agricultural lands (paddy fields, upland crop fields, and orchards). In paddy fields and managed grasslands, relatively greater levels of plant residue input were estimated compared with those in upland crop fields and orchards, reflecting application of rice straw to soils and turnover of below ground biomass of perennial grasses, in paddy fields and managed grasslands, respectively (Fig. 4a).

The sum of organic carbon input in unmanaged grasslands was found to have increased with time and has become the largest amongst all land-use types in 2008 (Fig. 4b). This was caused by an increase in the area of the unmanaged grasslands, which was considered as a result of large conversions of other land-use types, such as paddy fields, orchards, and upland fields, to unmanaged grasslands through abandonment (Fig. 3).

The amount of total organic carbon input to the agricultural lands in Japan, the entire set of land used in the simulation, was found to have increased from 1970 to 1990-2000 (Table 2), mostly due to the increase in plant residue input in managed grassland as well as the increase in manure input in managed grasslands (Fig. 4b). Subsequently, the total organic carbon input was found to have decreased during 2000 and 2008 (Table 2), which was explained mostly by a decline in manure input in managed grasslands (Fig. 4b).

\subsection{Soil organic carbon stock change}

Simulated total SOC stock in agricultural lands in Japan (sum of SOC stock among all land-use types) decreased continuously from 488 to $458 \mathrm{Tg} \mathrm{C}$ between 1970 and 2006 (Fig. 5b). Andosols were found to have been increasing its SOC stock, though only slightly, from 134 to $136 \mathrm{Tg} \mathrm{C}$ (Fig. 5a). Whereas all soil groups except Andosols were found to have been decreasing their SOC stock.

The rate of changes in the total SOC stock in agricultural lands in Japan evaluated with 10 year intervals were estimated to be $-0.95 \mathrm{Tg} \mathrm{Cyr}^{-1}$ in 1980-1990 (negative sign indicates loss of SOC with time) (Fig. 6). A greater loss of $\mathrm{SOC}$, equal to $-1.06 \mathrm{Tg} \mathrm{Cyr}^{-1}$, was found subsequently in 1990-2000.

Rate of SOC stock change per unit area was found to be negative in all land-use types except managed grasslands and unmanaged grasslands (Fig. 6, left). The greatest rate of SOC loss (i.e. $\mathrm{CO}_{2}$ source) was found in settlements and other lands, whereas the greatest rate of SOC gain (i.e. $\mathrm{CO}_{2}$ sink) was found in managed grasslands. In each different land-use type, changes in the rate of SOC loss or gain between 1980 1990 and 1990-2000 were only relatively small (Fig. 6, left).

Taking into account the changing area of a certain landuse type over time, rate of changes in the sum of SOC stocks in lands belonging to the same land-use type in a certain period (hereafter refereed as "apparent SOC loss" (or gain) for simplicity) was evaluated with 10 year intervals. Upland crop fields and settlements were found to have apparent SOC loss (i.e. $\mathrm{CO}_{2}$ source) which increased relatively sharply between 1980 and 2000 (Fig. 6). This occurred along with the increase in the area of these land-use types (Fig. 3), and with relatively small changes in the rate of SOC stock change per a unit area (Fig. 6, left). Managed grasslands were found to have the greatest apparent $\mathrm{SOC}$ gain (i.e. $\mathrm{CO}_{2}$ sink), which increased slightly from 1980-1990 to 1990-2000. This occurred along with a small increase in the rate of SOC stock change per unit area (Fig. 6, left), and with only small changes in the area of this land-use (Fig. 3). 

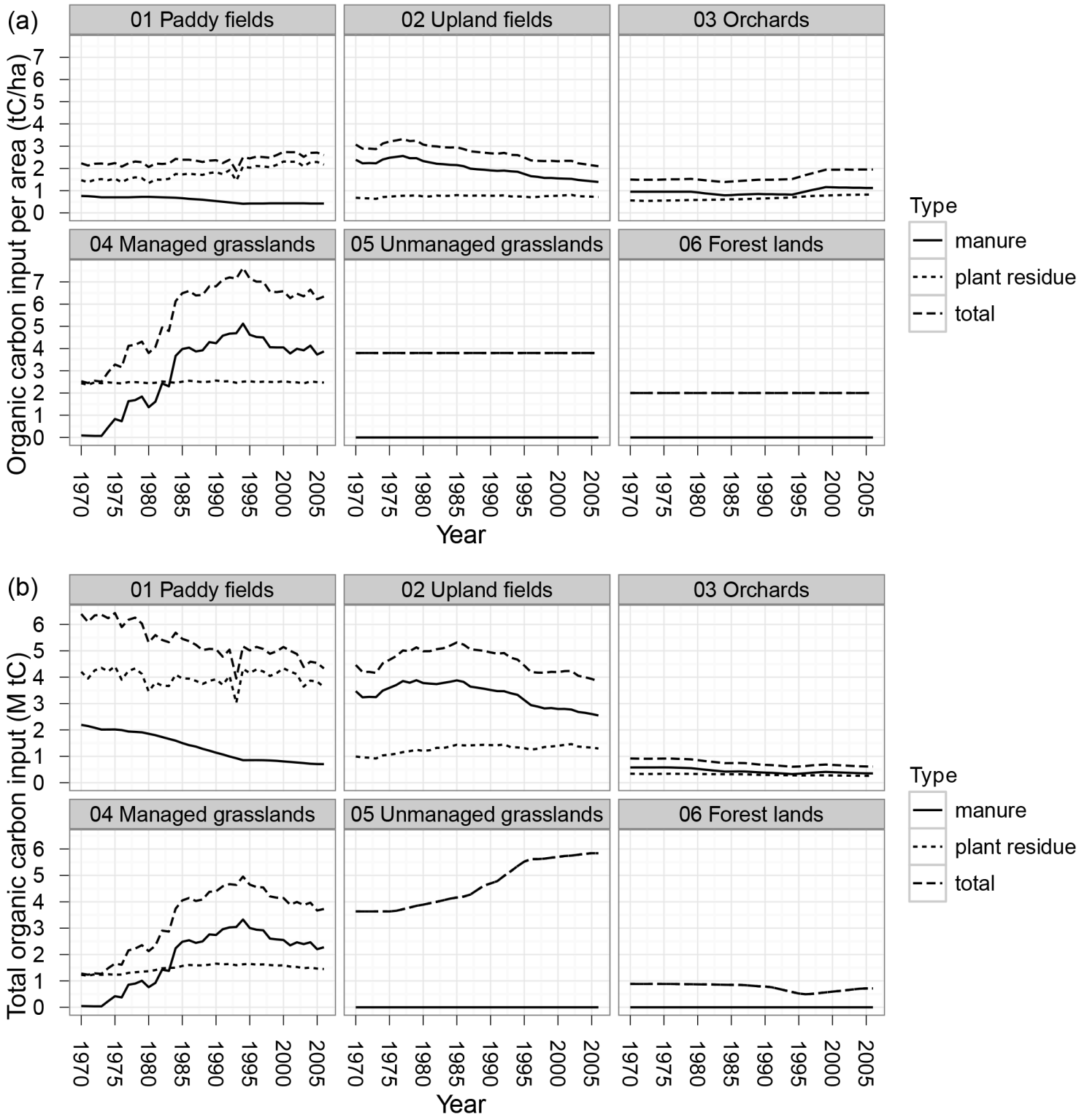

Figure 4. Input of organic carbon to soils via incorporation of plant residues and application of manure (including slurry and excreta), expressed as annual input rate per unit area of soils (a) and annual total sum (b), in different land-use types during 1970-2008.

\subsection{Validation of model simulation in 1979-1998}

Weighted mean concentrations of simulated SOC stock calculated for each of the seven major soil groups under four different land-use types of agricultural lands during 1979-1998 showed a continuously decreasing trend in most soil groups and land-use types except Andosols and Wet Andosols under upland crop fields as well as all soil groups under managed grasslands (Fig. 7). Whereas those of observed SOC stock showed (1) a slightly decreasing trend in most soil groups under paddy fields and upland crop fields, and (2) a slightly increasing trend in all three soil groups under orchards (Fig. 7).
With respect to the goodness of agreement of simulated and observed SOC stock, relatively good agreement was found in paddy fields and upland crop fields, except for in Wet Andosols under paddy fields in which simulated SOC stock resulted in overestimation (Fig. 7). On the other hand, in orchards, simulated SOC stock resulted in underestimation in all three soil groups for which the validation was conducted (Fig. 7). For managed grasslands, weighted mean concentration of the observed SOC stock could not be obtained due to limited data availability. 
Table 2. Amount of organic carbon from different sources applied to soils in agricultural lands of Japan, employed in simulation (unit: $\left.\mathrm{GgC}_{\mathrm{yr}}^{-1}\right)$.

\begin{tabular}{lrrrrr}
\hline & 1970 & 1980 & 1990 & 2000 & 2008 \\
\hline Manure & 6225 & 6869 & 7717 & 6497 & 5825 \\
Slurry $^{1}$ & 64 & 67 & 75 & 66 & 58 \\
Excreta $^{1}$ & 54 & 40 & 47 & 49 & 46 \\
RSD $^{2}$ & 11286 & 11122 & 12779 & 13895 & 13486 \\
Total & 17629 & 18098 & 20618 & 20507 & 19415 \\
\hline
\end{tabular}

${ }^{1}$ A conversion factor of 0.5 was applied for above listed values of slurry and excreta prior to determination of the annual input of farm-yard manure in RothC simulation to take account relatively fast decomposition of these organic matters compared to composted manure.

2 RSD: plant residue.

\section{Discussions}

\subsection{Historical trend of soil carbon stock change}

With respect to the trends of apparent SOC loss estimated for each of different land-use types in historical periods, multiple factors were considered to have influence on it. First, the relatively rapid increase in upland crop fields was attributed to increase in area (Fig. 3) combined with decline in manure input (Fig. 4a). Also, conversion of paddy fields to upland crop fields which occurred from 1970s to 2008 (Fig. 3) lead to enhancement of SOM decomposition under aerobic conditions. Second, increase in the apparent SOC loss in both settlements and other lands were attributed to area expansion due to a large conversion of agricultural fields (paddy fields, upland crop fields, orchards, and managed grasslands) to these land-use types (Fig. 3), combined with no organic carbon input assumed for both of the land-use types. Third, decline in paddy fields was attributed to a rapid and large decline in area (Fig. 3). With respect to the increasing trend of apparent SOC gain found in managed grasslands (Fig. 6), the increase in manure input was considered to have been a strong influence (Fig. 4a). The sum of $\mathrm{CO}_{2}$ emissions from settlements and other lands were comparable to that from upland crop fields and found to be a major $\mathrm{CO}_{2}$ emission source among all other land-use types (Fig. 6).

\subsection{Performance and potential of simulation system}

The weighted mean values of the simulated SOC stocks calculated for several major soil groups under paddy fields and upland crop fields were comparable to those calculated for observations in nation-wide stationary monitoring conducted during 1979-1998 (Fig. 6). Sum of the area of these soil groups for which validation was conducted was $2.6 \mathrm{Mha}$, accounting for $54.4 \%$ of the total area of agricultural lands (paddy fields, upland crop fields, orchards, and managed grasslands) used in the simulation.

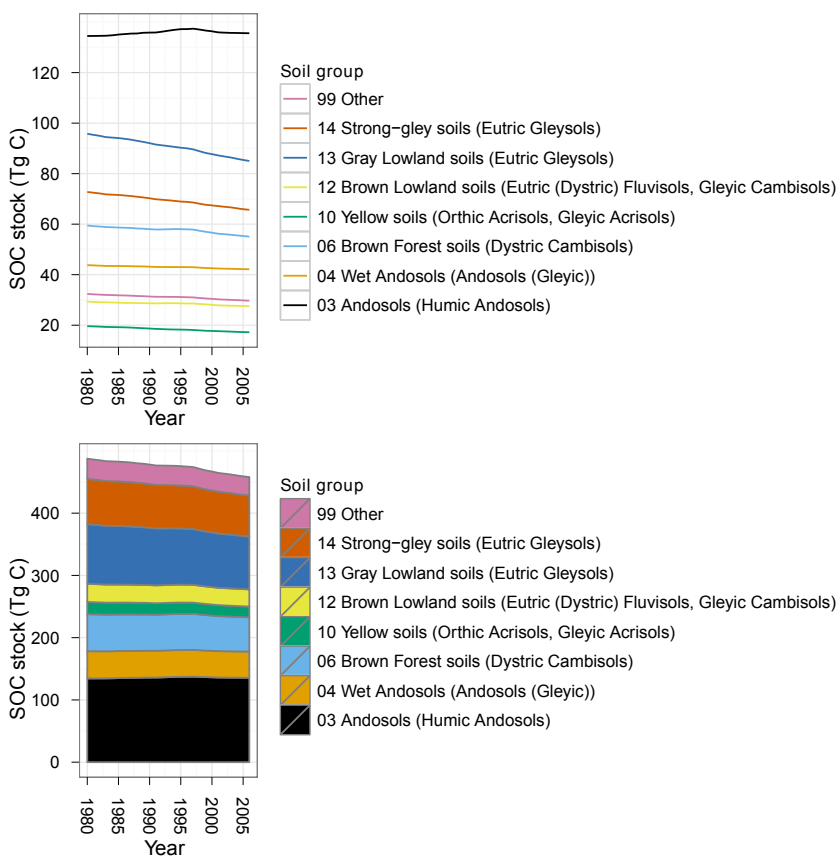

Figure 5. Simulation output on changes in soil organic carbon (SOC) stocks in agricultural lands in Japan. Top panel shows SOC stock in seven selected major soil groups and other soil groups. Bottom panel shows both the total sum and individual value of SOC stock in each of those soil groups as a stacked area graph. Note that the selected seven major soil groups accounts for $88 \%$ of total area of all 16 soil groups in Japan, according to Obara (2000).
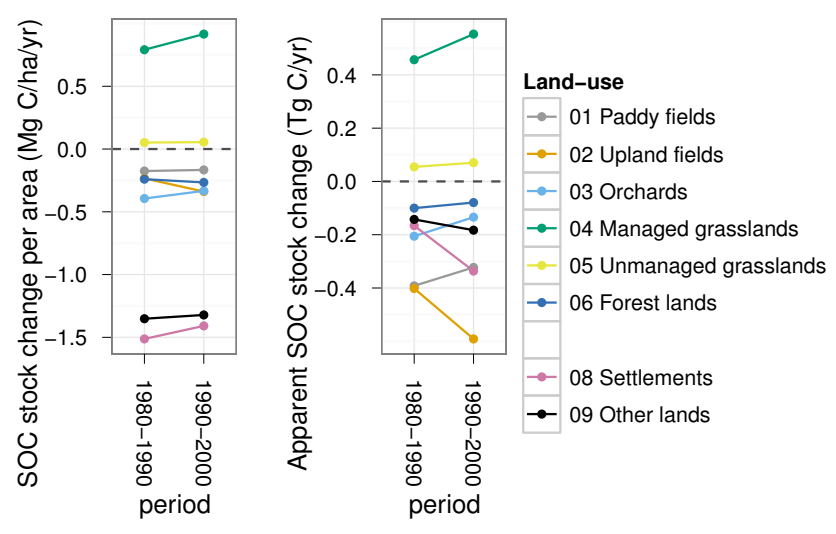

Figure 6. Rate of apparent soil organic carbon (SOC) stock changes in different land use and period during 1980-2008. Left panel shows annual rate of SOC stock change per area of each land-use type. Right panel shows annual rate of apparent SOC stock change of each land use with varying area. Note that for the apparent SOC stock change (right panel), increase in the area of a certain landuse type, occurred with no change in the rate of SOC stock change per area and will result in an increase in the quantity of this landuse type. The rate is expressed as a 10 year mean value. Positive and negative values on vertical axis indicate a gain and loss of SOC stock, which are equivalent to $\mathrm{CO}_{2}$ removal from and emission to the atmosphere, respectively. 


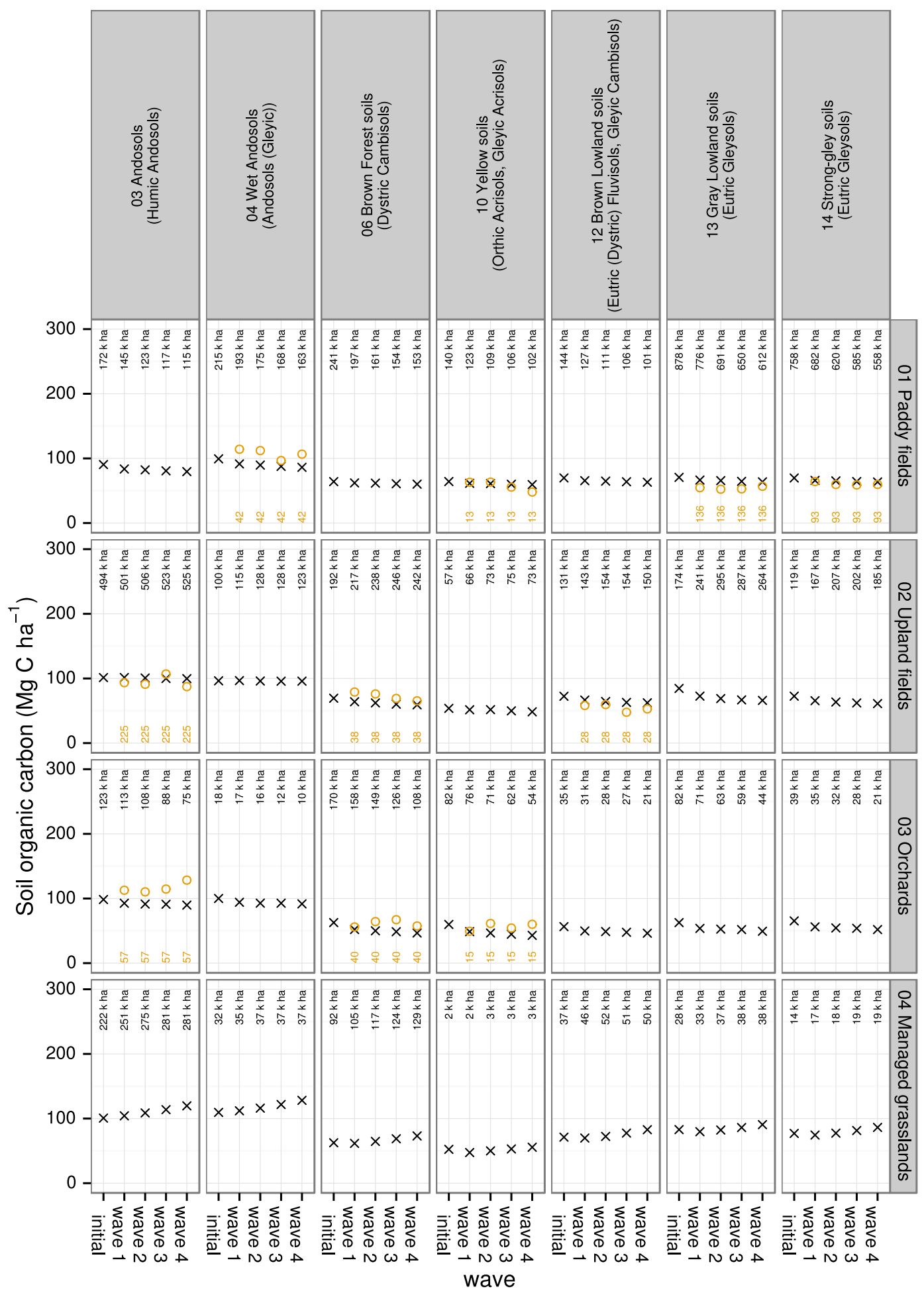

Figure 7. Temporal changes in the weighted mean concentration of soil organic carbon (SOC) calculated for seven major soil groups (linedup horizontally) under different land-use types (lined-up vertically) in agricultural lands in Japan. Simulated SOC stock (black cross) were superimposed on observed data from the Basic Soil Environment Monitoring Project, stationary monitoring conducted during 1979-1998 (ocher circle). Black figure labels above black cross indicate area of land accounted for in the calculation of the weighted mean concentration of simulated SOC, in unit of kilo hectare. Ocher figure labels below ocher circle indicate number of samples used to calculate the weighted mean concentration of SOC in the monitoring. Relative area distribution of soil groups are as follows: 03 Andosols - $21 \%, 04$ Wet Andosols - 7 \%, 06 Brown Forest Soils - 14\%, 10 Yellow Soils - 5\%, 12 Brown Lowland Soils: $7 \%$, 13 Gray Lowland Soils: $22 \%$, 14 Gley Lowland Soils $-17 \%$. Years of each survey wave (horizontal axis in each plot) are as follows: initial - 1970, wave 1-1979-1983, wave 2-1984-1988, wave 3 - 1989-1993, wave 4 - 1994-1998. 
In orchards, however, simulated SOC stock change were found to be somewhat underestimated compared to observations in the monitoring (Fig. 6). In orchards, the calculation of organic carbon input to soils by the DTK set the concentration organic carbon of plant residues in orchards equaled to $40 \%$, similar to that in crop residues (Shirato and Yagasaki, 2012a, b, 2013). As this value is rather lower compared with data reported for fruit trees by Nakamura and Yuyama (2005) (e.g. leaves and pruned branches of chestnut and loquat, in the range of 49-51\%), settings for the organic carbon concentration of plant residues in orchards in the DTK may need revision. Furthermore, applicability of RothC model to soils under no-till management in orchards to simulate SOC stock change at the depth of 0-30 cm may need further consideration and validation as this model deals with only one soil layer.

Soil groups and land-use types for which validation was conducted by comparing simulated SOC stock with observations in stationary monitoring (Fig. 6) were equivalent to $2.98 \mathrm{M}$ ha of the land area in Japan. This geographical entity accounted for $61.5 \%$ of total area of agricultural lands (paddy fields, upland crop fields, orchards, and managed grasslands) and $44.5 \%$ of total area used in the simulation.

With respect to data handling in SOC stock calculation for stationary monitoring, for three land-use types under agricultural usages (paddy fields, upland crop fields, and orchards) for which validation was conducted, this study employed a rather strict strategy on data quality control which included only soil samples having measurements of both bulk density and SOC concentration. As a result, many soil samples in the database having measurements of only one of either bulk density or SOC concentration were excluded prior to calculation of weighted mean concentration of SOC stock. This may lead to the risk of potential spatial bias in calculation of the mean concentration of SOC stock due to a limited number of samples.

Simulation results indicated that, at country scale, managed grasslands and settlements have likely been a major sink and source, respectively, of $\mathrm{CO}_{2}$ emission due to SOC stock change; validation of the model simulation on SOC stock change in these land-use types remains forthcoming challenges.

\section{Summary}

The overall rate of SOC stock change in agricultural lands in Japan during the historical period from 1970 to 2008, simulated with our newly developed system integrating processbased model on SOC dynamics and spatio-temporal inventories of soil, climate, land-use changes and agricultural activities, was shown likely to be net negative (i.e. releasing $\mathrm{CO}_{2}$ to the atmosphere as $\mathrm{CO}_{2}$ source) ranging around -0.95 to $-1.05 \mathrm{Tg} \mathrm{Cyr}^{-1}$. At country-level mean basis, the simulation indicated that managed grasslands have likely been se- questrating $\mathrm{SOC}$ (i.e. $\mathrm{CO}_{2}$ sink) with an influence of relatively greater rate of organic carbon input to soils estimated for this land-use type. Whereas most of soil groups under upland crop fields were shown to have been losing SOC (i.e. $\mathrm{CO}_{2}$ source), except for Andosols in which the SOC level was shown to have been maintained or sequestrated slightly over the time.

Relatively good agreement between simulated and observed mean SOC stocks were found in several major soil groups under paddy fields and upland crop fields with relatively large area distribution. This supported effectiveness of the simulation system to predict changes in countryscale SOC stock in lands under these land uses over several decades. On the other hand, for soils under other land-use types such as orchards and managed grasslands, validation of the simulation system will have to be conducted in a future study, especially before this system will be fully applied to regions or countries where these land-use types are dominant in agricultural lands. In particular, as the results of simulation indicated that SOC stock change under managed grasslands and settlements have likely been a major sink and source of $\mathrm{CO}_{2}$ emission at country scale, respectively, validation of SOC stock change under these land-use types, which could not have been accomplished due to limited availability or a lack of measurement, remains a forthcoming challenge.

\section{The Supplement related to this article is available online at doi:10.5194/bg-11-4429-2014-supplement.}

Acknowledgements. Authors acknowledge to two anonymous referees for their comment and advice useful to improve the quality of our paper. We also acknowledge to Shigeto Sudo at National Institute for Agro-Environmental Sciences (NIAES) for his assistance in setting up server computing system and database environment for simulation and processing of geographical information, Kazuyuki Yagi at NIAES for useful comments to improve quality of manuscript, Hiroshi Obara and Yusuke Takata at NIAES for providing soil gravel content data set collected in the recent soil survey project in Japan. This work was funded by the research project Development of Mitigation and Adaptation Techniques to Global Warming in the Sectors of Agriculture, Forestry, and Fisheries, the Ministry of Agriculture, Forestry and Fisheries, Japan.

Edited by: A. Neftel 


\section{References}

Agricultural Production Bureau, Ministry of Agriculture Forestry and Fisheries: Dojou hozen chousa jigyou seisekisyo, 2008.

Coleman, K. and Jenkinson, D. S.: ROTHC-26.3 A model for the turnover of carbon in soil: Model description and windows users guide, November 1999 issue, IACR Rothamsted, available at: http://www.rothamsted.ac.uk/ssgs/RothC/mod26_3_win.pdf, 1999.

Eglin, T., Ciais, P., Piao, S. L., Barre, P., Bellassen, V., Cadule, P., Chenu, C., Gasser, T., Koven, C., Reichstein, M., and Smith, P.: Historical and future perspectives of global soil carbon response to climate and land-use changes, Tellus B, 62, 700-718, doi:10.1111/j.1600-0889.2010.00499.x, 2010.

Houghton, R. A.: Revised estimates of the annual net flux of carbon to the atmosphere from changes in land use and land management 1850-2000, Tellus B, 55, 378-390, doi:10.1034/j.16000889.2003.01450.x, 2003.

Houghton, R. A., Hackler, J. L., and Lawrence, K. T.: The U.S. carbon budget: contributions from land-use change, Science, 285, 5427, doi:10.1126/science.285.5427.574, 1999.

Intergovernmental Panel on Climate Change: Good practice guidance for land use, land-use change and forestry, edited by: Penman, J., Gytarsky, M., Hiraishi, T., Krug, T., Kruger, D., Pipatti, R., Buendia, L., Miwa, K., Ngara, T., Tanabe, K., and Wagner, F., Institute for Global Environmental Strategies for the IPCC, Hayama, Kanagawa, Japan, 2003.

Janssens, I. A., Freibauer, A., Schlamadinger, B., Ceulemans, R., Ciais, P., Dolman, A. J., Heimann, M., Nabuurs, G.-J., Smith, P., Valentini, R., and Schulze, E.-D.: The carbon budget of terrestrial ecosystems at country-scale - a European case study, Biogeosciences, 2, 15-26, doi:10.5194/bg-2-15-2005, 2005.

Jenkinson, D. S., Andrew, S. P. S., Lynch, J. M., Goss, M. J., and Tinker, P. B.: The turnover of organic carbon and nitrogen in soil [and discussion], Philos. T. R. Soc. Lond. B. Biol. Sci., 329, 1255, doi:10.1098/rstb.1990.0177, 1990.

Koga, N., Smith, P., Yeluripati, J. B., Shirato, Y., Kimura, S. D., and Nemoto, M.: Estimating net primary production and annual plant carbon inputs, and modelling future changes in soil carbon stocks in arable farmlands of northern Japan, Agric. Ecosyst. Environ., 144, 51-60, doi:10.1016/j.agee.2011.07.019, 2011.

Lal, R.: Soil carbon sequestration to mitigate climate change, Geoderma, 123, 1-22, doi:10.1016/j.geoderma.2004.01.032, 2004.

Lehmann, J.: Biological carbon sequestration must and can be a win-win approach, Clim. Change, 97, 459-463, doi:10.1007/s10584-009-9695-y, 2009.

Li, C., Zhuang, Y., Frolking, S., Galloway, J., Harriss, R., Moore III, B., Schimel, D., and Wang, X.: Modeling soil organic carbon change in croplands of China, Ecol. Appl., 13, 327-336, 2003.

Mondini, C., Coleman, K. and Whitmore, A. P.: Spatially explicit modelling of changes in soil organic $\mathrm{C}$ in agricultural soils in Italy, 2001-2100: Potential for compost amendment, Agr. Ecosyst. Environ., 153, 24-32, doi:10.1016/j.agee.2012.02.020, 2012.

Nakamura, M. and Yuyama, Y.: Development of a composition database for various types of biomass, Tech. Rep. Natl. Inst. Rural Eng., 203, 57-80, 2005.

National Institute for Agricultural Sciences: Classification system for cultivated soils based on soil series, revised 2nd approximation, available at: http://soilgc.job.affrc.go.jp/, 1983.
Nihon Dojo Kyoukai: Chiryoku hozen dojouzu de-ta CD-ROM (Zenkoku-ban), 2002.

Obara, H.: Outline of the soil monitoring and soil quality changes of the arable land in Japan, Pedologist, 44, 134-142, 2000.

Okada, M., Iizumi, T., Nishimori, M., and Yokozawa, M.: Mesh climate change data of Japan ver.2 for climate change impact assessments under IPCC SRES A1B and A2, J. Agric. Meteorol., 65, 97-109, doi:10.2480/agrmet.65.1.4, 2009.

Ondanka taisaku dojou kinou chousa kyougikai: Dojou yurai onsitsu kouka gas dojou tanso chousa jigyou houkokusyo, heisei 24 nendo, 2013.

Piao, S., Fang, J., Ciais, P., Peylin, P., Huang, Y., Sitch, S., and Wang, T.: The carbon balance of terrestrial ecosystems in China, Nature, 458, 1009-1013, doi:10.1038/nature07944, 2009.

PostgreSQL Global Development Group: PostgreSQL, available at: http://www.postgresql.org/, 2013.

Refractions Research Inc: PostGIS, Refractions Research Inc., Victoria, British Columbia, Canada, available at: http://postgis. refractions.net/, 2012.

Schulp, C. J. E., Nabuurs, G.-J., and Verburg, P. H.: Future carbon sequestration in Europe-Effects of land use change, Agr. Ecosyst. Environ., 127, 251-264, doi:10.1016/j.agee.2008.04.010, 2008.

Seino, H.: An estimation of distribution of meteorological elements using GIS and AMeDAS data, J. Agr. Meteorol., 48, 379-383, 1993.

Shirato, Y. and Yagasaki, Y.: Simulating soil carbon in Japanese agricultural land by the Rothamsted carbon model, Tsukuba, Japan, available at: http://www.niaes.affrc.go.jp/ marco/marco2012/pdf/ws3_27_shirato.pdf, 2012a.

Shirato, Y. and Yagasaki, Y.: Simulating soil organic carbon stock change in Japanese agricultural land with the RothC model, p. 289, Bari, Italy, available at: http://www.scienzadelsuolo.org/ _docs/Atti_Eurosoil_2012.pdf, 2012b.

Shirato, Y. and Yagasaki, Y.: Estimating carbon sequestration potential of cropland management in Japanese arable soils with the Rothamsted carbon model, p. 85, Madison, Wisconsin, USA, available at: http://iuss-c-conference.org/IUSS_Global_Soil_C_ Conference_program.pdf, 2013.

Shirato, Y. and Yokozawa, M.: Applying the Rothamsted Carbon Model for long-term experiments on Japanese paddy soils and modifying it by simple tuning of the decomposition rate, Soil Sci. Plant Nutr., 51, 405-415, 2005.

Shirato, Y., Hakamata, T., and Taniyama, I.: Modified Rothamsted Carbon Model for Andosols and its validation: changing humus decomposition rate constant with pyrophosphate-extractable Al, Soil Sci. Plant Nutr., 50, 149 158, doi:10.1080/00380768.2004.10408463, 2004.

Sitch, S., Huntingford, C., Gedney, N., Levy, P. E., Lomas, M., Piao, S. L., Betts, R., Ciais, P., Cox, P., Friedlingstein, P., Jones, C. D., Prentice, I. C., and Woodward, F. I.: Evaluation of the terrestrial carbon cycle, future plant geography and climate-carbon cycle feedbacks using five Dynamic Global Vegetation Models (DGVMs), Glob. Change Biol., 14, 2015-2039, doi:10.1111/j.1365-2486.2008.01626.x, 2008.

Smith, P., Martino, D., Cai, Z., Gwary, D., Janzen, H., Kumar, P., McCarl, B., Ogle, S., O’Mara, F., Rice, C., Scholes, B., Sirotenko, O., Howden, M., McAllister, T., Pan, G., Romanenkov, V., Schneider, U., Towprayoon, S., Wattenbach, M., and 
Smith, J.: Greenhouse gas mitigation in agriculture, Philos. T. R. Soc. B Biol. Sci., 363, 789-813, doi:10.1098/rstb.2007.2184, 2008.

Yagasaki, Y. and Shirato, Y.: Assessment on the rates and potentials of soil organic carbon sequestration in agricultural lands in Japan using a process-based model and spatially explicit land-use change inventories - Part 2: Future potentials, Biogeosciences, 11, 4443-4457, doi:10.5194/bg-11-4443-2014, 2014.
Takata, Y., Ito, T., Ohkura, T., Obara, H., Kohyama, K., and Shirato, Y.: Phosphate adsorption coefficient can improve the validity of RothC model for Andosols, Soil Sci. Plant Nutr., 57, 421-428, doi:10.1080/00380768.2011.584510, 2011.

Thornthwaite, C. W.: An approach toward a rational classification of climate, Geogr. Rev., 38, 55-94, 1948. 